\title{
Effects of increased rumen fill and restricted feeding on alimentary behaviour and rumen function in cows
}

\author{
R Baumont, J Jamot, C Dardillat \\ INRA, Station de Recherches sur la Nutrition des Herbivores, \\ Theix, 63122 Saint-Genès-Champanelle, France
}

Rumen fill is known to limit forage intake capacity, but digesta consistency may also be involved in the physical control of intake. In this experiment, rumen fill was increased with plastic flasks, placed in the dorsal sac or in the ventral sac in order to specifically modify digesta consistency. The effects on intake behaviour and rumen function were compared with those obtained by restricting feeding.

Rumen fill was increased by 10 plastic flasks (total volume $12 \mathrm{l}$ ) with a density of 0.8 (treatment LD; flasks in the dorsal sac) or 1.2 (treatment HD, flasks in the ventral sac). The flasks were bound together and placed in the rumen for $3 \mathrm{~d}$ and then removed. The restricted hay feeding (treatment RH) at the intake level observed with $L D$ and $H D$, also was applied for $3 \mathrm{~d}$. Each treatment was repeated during 2 subsequent weeks, with at least $3 \mathrm{~d}$ between repetitions. The treatments (control, LD, HD and RH) were performed successively on 4 ruminally fistulated, dry Jersey cows fed ad libitum with orchard grass hay (715 g NDF/kg DM) once daily at $09.00 \mathrm{~h}$. Daily intake was recorded during the whole experi- ment. No significant differences were found between the control period and the days preceeding treatments $L D, H D$ or $R H$. The kinetics of intake, the alimentary behaviour ( $6 \mathrm{~d}$ during $\mathrm{C}$ and $5 \mathrm{~d}$ during the treatments weeks), the rumen fill at 09.00 and $16.00 \mathrm{~h}$ and the liquid turnover rate were all measured.

Increasing the rumen fill by $12 \mathrm{l}$, which represented $20 \%$ of rumen volume at $09.00 \mathrm{~h}$, reduced intake capacity by $22 \%$ (table I). Rumen fill appeared to act as a satiation factor by reducing the time spent eating during the $2 \mathrm{~h}$ following the distribution $(90,69$ and $62 \mathrm{~min}$ for C, LD and HD respectively, $P<0.05$ ) and by reducing eating rate (table I). No differences were found between treatment $L D$ and $H D$. Increasing rumen fill slightly decreased rumination time and increased rumination time per $\mathrm{kg}$ eaten by $19 \%$. In contrast, neither the eating rate nor the rumination time per $\mathrm{kg}$ eaten was affected by $\mathrm{RH}$. Both increasing rumen fill as well as $\mathrm{RH}$ increased particulate turnover rate (table I), without modification of liquid turnover rate. As a result, rumen dry matter content decreased.

Table I. Effects of increasing rumen fill by plastic flasks of low density (LD) or high density (HD) and by restricting hay feeding $(\mathrm{RH})$.

\begin{tabular}{lccccc}
\hline & Control & $L D$ & $H D$ & $R H$ & $R S D^{\mathrm{d}}$ \\
\hline & & & & & \\
& & & & & \\
Daily intake $(\mathrm{kg} \mathrm{DM})$ & $23.7^{\mathrm{a}}$ & $5.97^{\mathrm{b}}$ & $5.6^{\mathrm{b}}$ & $5.98^{\mathrm{b}}$ & 0.38 \\
Eating rate $(\mathrm{g} \mathrm{DM} / \mathrm{min})$ & $20.2^{\mathrm{b}}$ & $19.5^{\mathrm{b}}$ & $25.5^{\mathrm{a}}$ & 1.63 \\
Rumination time $(\mathrm{min} / \mathrm{kg}$ eaten) & $78.1^{\mathrm{a}}$ & $90.3^{\mathrm{ab}}$ & $95.6^{\mathrm{b}}$ & $80.1^{\mathrm{a}}$ & 7.77 \\
Mean rumen fill $(\mathrm{kg})^{\mathrm{e}}$ & $63.1^{\mathrm{ab}}$ & $65.3^{\mathrm{bc}}$ & $69.1^{\mathrm{c}}$ & $59.7^{\mathrm{a}}$ & 3.2 \\
Mean rumen dry matter content $(\%)$ & $11.8^{\mathrm{a}}$ & $8.7^{\mathrm{b}}$ & $9.0^{\mathrm{b}}$ & $9.3^{\mathrm{b}}$ & 0.51 \\
ADL turnover rate $(\% / \mathrm{h})$ & $2.10^{\mathrm{a}}$ & $2.94^{\mathrm{b}}$ & $2.83^{\mathrm{bc}}$ & $2.5^{\mathrm{c}}$ & 0.19 \\
Liquid turnover rate $(\% / \mathrm{h})$ & 11.0 & 10.9 & 10.7 & 10.8 & 0.74 \\
\hline
\end{tabular}

a, b. c Means without a common superscript differ $(P<0.05)$. ${ }^{\star}$ RSD residual standard deviation of the analysis of variance; ${ }^{e}$ including the flasks. 